\title{
MUNDO OBRERO, CULTURA Y ASOCIACIONISMO: ALGUNAS REFLEXIONES SOBRE MODELOS Y PERVIVENCIAS FORMALES
}

\author{
por \\ JAVIER NAVARRO NAVARRO \\ Universitat de València
}

RESUMEN: El autor realiza en este artículo algunas reflexiones sobre los modelos asociativos escogidos por los medios obreros y populares españoles desde mediados del siglo XIX para la defensa de sus intereses, especialmente por lo que se refiere a la difusión de la cultura y la instrucción. Cabe destacar, entre otros hechos, la pervivencia y éxito de determinados prototipos heredados, como es el caso del «ateneo» basta los años de la guerra civil. Al mismo tiempo, las organizaciones y entidades obreras intentarán satisfacer las demandas educativas y de ocio de sus afiliados y de los trabajadores en general desarrollando centros multifuncionales que pudieran responder a todos estos requisitos. Un ejemplo de ello serán las «Casas del Pueblo» levantadas por el movimiento socialista.

Palabras clave: Anarquismo. Asociacionismo. España. Movimiento Obrero. Siglos XIX y XX. Sociabilidad. Socialismo.

ABSTRACT: In this article, the author reflects on the associative models chosen by spanish working and popular classes since the middle of nineteenth century in order to defend their interests, especially in the case of the difussion of culture and education. It is remarkable the continuity and success of some inherited prototypes, as it happened with the "ateneos» until the years of the spanish civil war. At the same time, workers' organizations tried to satisfy an extensive range of demands by developing multifunctional centres. Examples of these were the "Casas del Pueblo» (People's Houses) erected by the socialist movement.

KeY WORDS: Spain. $19^{\text {th }}$ Century. $20^{\text {th }}$ Century. Labor movement. Socialism. Anarchism. Associations. Sociability. 
En el marco de esta contribución, nos proponemos acercarnos a los modelos asociativos escogidos por los medios obreros y populares españoles desde mediados del siglo XIX para la defensa de sus intereses, especialmente por lo que se refiere a la difusión de la cultura y la instrucción.

Cabe destacar, entre otros hechos, la pervivencia y el éxito de determinados prototipos heredados, como es el caso del «ateneo», hasta los años de la guerra civil. Al mismo tiempo, las organizaciones y las entidades obreras intentarán satisfacer las demandas educativas y de ocio de sus afiliados y de los trabajadores, desarrollando en general centros multifuncionales que pudieran responder a todos estos requisitos. Un ejemplo de ello serán las «Casas del Pueblo» levantadas por el movimiento socialista.

\section{Clases POPUlaReS y MODELOS ASOCIATIVOS}

La clase social constituye una de las variables fundamentales - aunque ni mucho menos la única - a la hora de explicar bastantes de los mecanismos profundos que intervienen en la estructuración y dinámica del fenómeno asociativo a lo largo de la época contemporánea. En el caso de España, y desde el siglo XIX, las capas populares impulsaron propuestas asociativas en ámbitos como «la actividad social o política, la economía social, el ocio o la cultura», según palabras de Jorge Uría ${ }^{1}$. No obstante, este historiador advierte de que conviene matizar la percepción de que estas sociedades y entidades fueron, sin más, expresiones puras y espontáneas de la voluntad asociativa popular ${ }^{2}$. De hecho, muchas de ellas surgieron (conviene no olvidarlo) promovidas, creadas o encauzadas por otros grupos sociales o tuvieron una orientación interclasista.

En general, la puesta en marcha de un entramado societario de carácter popular y obrero desde mediados del siglo XIX tenía varios ejes inspiradores. En primer lugar, la lucha por la satisfacción de unas necesidades básicas no cubiertas por la oferta estatal, unas carencias que intentaban paliarse desde la solidaridad y la autodefensa. Pere Solà afirma, en este sentido, que «històricament, l'associacionisme obrer essencialment té a veure amb temes clau com: 1) treball, 2) defensa de la salut i d'unes condicions de vida dignes i suficients ('previsió social' se n'ha dit d'això), i 3) ocupació de l'oci»3. Esta sociabilidad cumplía además otros objetivos fundamentales: aglutinar a los miembros del grupo en puntos de interés múltiple compartido, facilitar las actividades solidarias y, en definitiva, crear lazos de identidad y pertenencia a un determinado

1 URÍA, Jorge: «En torno a las comunicaciones presentadas a asociacionismo», en CASTILLO, Santiago y OrTIz De ORRUÑo, José María (Eds.): Estado, protesta y movimientos sociales, Bilbao, Asociación de Historia Social-Universidad del País Vasco, 1998, pp. 346-347.

2 Ibid., pp. 347 y $350-351$

3 SOLÀ, Pere: «L'associacionisme obrer a la història de la societat catalana», L'Avenç, Barcelona, $n^{\circ} 171$, Junio de 1993, p. 28.

Hispania, LXIII/2, núm. 214 (2003) 467-484 
grupo o movimiento social ${ }^{4}$. Es lógico pensar que a esta multiplicidad de intereses correspondería la creación de diferentes plataformas asociativas y formas de sociabilidad. Según Pere Solà - refiriéndose en concreto al caso de Cataluña-, las tres formas de asociacionismo popular más influyentes en la época contemporánea han sido históricamente: el relacionado con el recreo, el mutualismo en todas sus formas y variedades y el asociacionismo laboral ligado a las profesiones y a la defensa del trabajo5.

Aunque es cierto que algunas de estas modalidades asociativas populares (es el caso del mutualismo) pudieron servir para el desarrollo posterior de propuestas de carácter más reivindicativo, es verdad que todas ellas y sus diversas variantes (cooperativas, sociedades de oficios, ateneos, agrupaciones musicales y recreativas en general) experimentaron una continuidad a lo largo del tiempo que hará que en el futuro coexistan incluso fluidamente con las organizaciones del movimiento obrero y que de hecho este último no haga sino heredar y/o desarrollar buena parte de sus constantes formales.

A esta conclusión llega Pere Gabriel al perfilar una «tipología del asociacionismo popular» en Cataluña en el período 1868-1923, y en la que destacan, en opinión del historiador catalán, cuatro prototipos fundamentales en torno a los cuales se van a desplegar las plataformas asociativas puestas en marcha por el movimiento obrero o por la militancia más genéricamente popular: el casino (que puede presentar dos versiones: el «rico» y el «popular»), el ateneo (que surge «claramente abocado a una labor de instrucción popular, populista o no, desde una voluntad legal y apolítica»), la cooperativa y la sociedad de socorros mutuos ${ }^{6}$.

Pere Gabriel subraya en particular la persistencia de todo este entramado popular y obrero a lo largo de esos años, hecho que debe ser tenido en cuenta para explicar la vertebración política de los sectores populares desde las décadas finales del siglo XIX. Se trata de un asociacionismo, como vemos, de múltiples formas y carácter muy diverso, en buena medida polifuncional y en teoría «apolítico» y ecléctico. Este carácter abierto le permitía adaptarse a diferentes coyunturas políticas y legales - convirtiéndose así en la garantía de la continuidad de una vida política y un esfuerzo asociativo populares - y, sobre todo, «insertarse en un mundo popular no estrictamente partidista o sectario».

Por otra parte, este asociacionismo era, además, el «principal mecanismo de afirmación de una cultura popular compartida, básica si se quiere, que actuaba por debajo de las chillonas y cambiantes disputas de estrategias o programas de partido o tendencia» ${ }^{7}$. También el obrerismo y el republicanismo militantes

\footnotetext{
4 ANGUeRA, Pere: «Formes i espais de sociabilitat en una ciutat catalana: Reus a l'època contemporània», L'Avenç, Barcelona, $n^{\circ} 171$, Junio de 1993, pp. 62-67.

s SOLÀ, Pere: Itineraris per la sociabilitat meridional catalana: L'associacionisme i la cultura popular a la demarcació de Tarragona (1868-1964), Tarragona, Diputació de Tarragona, 1998, p. 27.

6 GABRIEL, Pere: «Sociabilidad obrera y popular y vida política en Cataluña, 1868-1923», Bulletin d' Histoire Contemporaine de l'Espagne, $\mathrm{n}^{\circ}$ 17-18, Junio-Diciembre de 1993, pp. 147-148.

7 Ibid., p. 151.
} 
asimilarán y reproducirán, a juicio de este historiador, ese modelo asociativo, lo cual revestirá especial importancia en el proceso de extensión del prototipo de centro multifuncional en el mundo obrero (y también en el republicano) desde finales del siglo XIX y principios del XX. Lo harán, en el caso de Cataluña, tanto las entidades levantadas por el republicanismo federal - que se consolidarán desde la década de 1880 - como el movimiento obrero de influencia anarcosindicalista en momentos de relativa estabilidad, como ocurrirá entre los años 1885 y $1893^{8}$.

Pero, ¿qué formas concretas adoptará y a qué modelos se adecuará el asociacionismo popular y obrero desde mediados del siglo XIX por lo que se refiere a la cultura y la instrucción? Como es sabido, las líneas maestras de comportamiento societario en la época contemporánea se fundamentan en las nuevas formas de sociabilidad originadas a partir de la Revolución francesa y asociadas en su desarrollo a la progresiva consolidación de la sociedad liberal. Las formas y espacios de sociabilidad creados por las clases populares y el naciente movimiento obrero durante los siglos XIX y XX se ubicarán en estos moldes culturales, reasimilándolos y readaptándolos en función de sus intereses.

Maurice Agulhon subraya este fenómeno de especialización, formalización y reapropiación por parte de las clases populares de modelos asociativos de las clases superiores. Para el historiador francés, el modelo que imitan los obreros - en su lucha por la conquista de un espacio propio- es el del círculo, pero diferenciado del círculo burgués, asimilado al ocio. Reivindican para ellos un «lugar donde el obrero satisfaga su necesidad de vida social sin ser tributario del cabaret o de sus dependencias, un lugar donde se disponga, gracias al poder económico de la asociación, de elementos de confort, un lugar donde se eduque gracias a una biblioteca»?. El círculo obrero nace pues en oposición al ocio «burgués» y a formas de diversión popular consideradas como degradantes (cabaret, taberna, etc.).

Por su parte, la tipología establecida por Jean-Louis Guereña para los aspectos formales de la vida asociativa en la España de la segunda mitad del siglo XIX revela, para este historiador, la existencia de dos arquetipos fundamenta-

\footnotetext{
8 Ibid., pp. 149-150. En torno a esta idea de la continuidad de la articulación asociativa popular y su influencia sobre el obrerismo y el republicanismo populares, pueden consultarse también los siguientes trabajos de GABRIEL, Pere: «Espacio urbano y articulación política popular en Barcelona, 1890-1920", en GARCíA DELGADO, José Luis (Ed.): Las ciudades en la modernización de España. Los decenios interseculares. VIII Coloquio de Historia Contemporánea de España dirigido por Manuel Tuñón de Lara, Madrid, Siglo XXI, 1992; «La Barcelona obrera y proletaria», en SÁNCHEZ, Alejandro (Ed.): Barcelona, 1888-1929. Modernidad, ambición y conflictos de una ciudad soñada, Madrid, Alianza Editorial, 1992, y «Sociabilitat de les classes treballadores a la Barcelona d'entreguerres, 1918-1936», en OYÓN, José Luis (Ed.): Vida obrera en la Barcelona de entreguerras, 1918-1936, Barcelona, Centre de Cultura Contemporània, 1998.

9 AGULHON, Maurice: "Classe ouvriére et sociabilité avant 1848», en Histoire vagabonde. I. Etbnologie et politique dans la France contemporaine, Paris, Éditions Gallimard, 1988, pp. 89-90.
}

Hispania, LXIII/2, núm. 214 (2003) 467-484 
les: el círculo de instrucción y de recreo (de procedencia liberal-burguesa) y la sociedad de socorros mutuos (plataforma societaria que está en el origen del movimiento obrero $)^{10}$. El círculo, por su parte, puede recibir el nombre de «ateneo» (acento puesto sobre la instrucción), «círculo» o «casino» (enfatizando así su carácter fundamentalmente recreativo). El círculo puede ser burgués o popular (en cuyo caso, los calificativos pueden ser múltiples: «obrero», «popular», etc.) y, respondiendo a su carácter bicéfalo, en él se practican tanto actividades culturales -lectura de periódicos y libros, cursillos, conferencias y debates, representaciones musicales y teatrales, etc.- como lúdicas: práctica de juegos autorizados, ingestión de bebidas en el café de la sociedad, charlas informales, etc.

Atendiendo a esta clasificación de tipo general, es evidente que existían dos modelos básicos «disponibles» para la configuración futura del prototipo del centro cultural obrero. Éstos respondían en general «a dues concepcions ben diferenciades de la voluntat associativa vuitcentista $»^{11}$. Se trataría, por un lado, de la asociación lúdica con un mínimo barniz cultural y, por otro, de la entidad cultural con escasa o nula concesión a la diversión por sí misma. Por lo general, la «mística culturizadora» característica del movimiento obrero otorgaría la primacía al segundo de ellos - el ateneo-, aunque ello no significa que se olvidaran, ni mucho menos, de las necesidades recreativas de afiliados y militantes.

Asistimos, por tanto, a partir de mediados del siglo XIX, a un proceso de apropiación y readaptación por parte de las clases populares y el movimiento obrero de las formas asociativas de carácter cultural creadas y desarrolladas por el liberalismo burgués decimonónico. Entre estas últimas, puede citarse, por ejemplo, el liceo, donde, según Jacques Maurice, «jóvenes de ambos sexos, pero siempre de buena familia se reúnen para practicar como aficionados el arte dramático y el arte lírico» ${ }^{12}$. Estas entidades se convertirían en muchos casos en ateneos (científicos, artísticos o literarios ${ }^{13}$ ) o círculos instructivos, que contaban con gabinetes de lectura de periódicos y bibliotecas y desarrollaban actividades como conferencias, tertulias, veladas literarias, teatrales o musicales, edición de alguna publicación, etc.

10 GUEREÑA, Jean-Louis: «Una aproximación a la sociabilidad popular: el caso de Asturias bajo la Restauración (1875-1900)», Estudios de Historia Social, Madrid, n $50-51$, Julio-Diciembre de 1989, pp. 201-202.

11 ANGUeRA, Pere: «Formes i espais de sociabilitat», op. cit., p. 64.

12 MAURICE, Jacques: «Propuestas para una historia de la sociabilidad en la España contemporánea», Estudios de Historia Social, Madrid, nº 50-51, Julio-Diciembre de 1989, p. 140.

13 Un ejemplo emblemático de estas entidades sería, por supuesto, el Ateneo Científico, Literario y Artístico de Madrid. Ver en general sobre estos ateneos, círculos y liceos: GuEREÑA, JeanLouis: «El asociacionismo cultural», en CARNERO, Guillermo (Ed.): Historia de la literatura española. Siglo XIX (I), Madrid, Espasa Calpe, 1997, pp. 9-15. 


\section{LOS ATENEOS}

Algunas de estas agrupaciones se abrirían progresivamente a las clases populares y desde la década de 1860 aparecerían asociaciones culturales que tenían entre sus principales objetivos la instrucción de aquéllas, todo lo cual coincidiría por otra parte con el obligado «repliegue cultural» al que se vieron sometidos los círculos progresistas, republicanos u obreristas en los últimos años del reinado de Isabel II (podemos citar como ejemplos de estos centros el Ateneo Catalán de la Clase Obrera, el Ateneo Igualadino de la Clase Obrera o el Ateneo Manresano de la Clase Obrera, entre otros, todos ellos fundados en la década de 1860 , sin olvidar, por supuesto, al célebre Fomento de las Artes madrileño $\left.{ }^{14}\right)$.

El modelo asociativo-cultural ateneísta se extendería a otras clases sociales y poco a poco se convertiría así en una instancia culturizadora relacionada y/o identificada con lo popular, aunque en principio mayoritariamente interclasista y de orientación reformista. De hecho, tal como señalan los investigadores del G.E.A.S. (Grupo de Estudios de Asociacionismo y Sociabilidad de la Universidad de Castilla-La Mancha), si el Ateneo aparece en un principio como «institución cultural por excelencia del liberalismo", a finales del siglo XIX el grupo más numeroso entre estas entidades (unos 58 en toda España hacia 1895) era el de los ateneos «obreros», bien creados por los propios trabajadores o bien promovidos por sectores sociales que "pretenden utilizar estos centros como instrumentos de control social» ${ }^{5}$.

De una u otra manera, y aunque puedan aparecer de otro tipo («católicos», "científicos» o «mercantiles»), las denominaciones de los ateneos hacia esos años hacen referencia mayoritariamente a su vinculación con las clases trabajadoras y a su labor en la instrucción de éstas. Se consolida así progresivamente un modelo cultural de centro instructivo que influirá decisivamente en el perfil del ateneo «popular» u «obrero», de tanto éxito en las últimas décadas del siglo XIX. Resulta interesante observar cómo, si bien el prototipo asociativo hegemónico será en general el casino «burgués», de finalidades fundamentalmente recreativas, el movimiento obrero preferirá adoptar en este terreno en el futuro - a medida que vaya planteando sus necesidades en materia cultural y recreativa- el modelo del círculo o ateneo de tendencia teóricamente instructiva y formativa. Los trabajadores organizados intentarán encauzar las actividades recreativas en un sentido "progresivo».

Esta «ética del tiempo libre» se convertirá en un sello distintivo del obrerismo. Tal como subraya Jean-Louis Guereña, en el imaginario obrero se iden-

14 GUEREÑA, Jean-Louis: «La sociabilidad en la España contemporánea», en SÁNCHEZ SÁNCHEZ, Isidro y VILLENA ESPINOSA, Rafael (Eds.): Sociabilidad fin de siglo. Espacios asociativos en torno a 1898, Cuenca, Ediciones de la Universidad de Castilla-La Mancha, 1999, pp. 36-39.

15 GEAS: España en sociedad. Las asociaciones a finales del siglo XIX, Cuenca, Ediciones de la Universidad de Castilla-La Mancha, 1998, pp. 40 y 68. 
tificará progresivamente el círculo de recreo burgués con la ociosidad y el círculo obrero con la educación popular:

«Los ateneos y casinos obreros reproducen formas precedentes de sociabilidad burguesa. Pero el recreo parece quedar en un segundo plano. Lo esencial es la instrucción, respuesta a una necesidad y a una demanda» ${ }^{16}$.

Sin embargo, cabe preguntarse si en realidad la crítica de la «ociosidad» burguesa excluía la atención a diferentes modalidades de recreo y uso del tiempo libre desde una perspectiva lúdica que el asociacionismo popular y obrero jamás abandonó en la práctica y que constituían en realidad la razón de ser de una parte nada desdeñable de la red societaria levantada por estos medios.

Surge así desde las últimas décadas del siglo XIX, como decíamos, todo un entramado de asociaciones específicamente culturales («ateneos», "centros de estudios", etc.), de diversas tendencias ideológicas, unidas, sin embargo, por un mismo propósito: la educación y culturización de las clases populares. JeanLouis Guereña ha puesto así de relieve la existencia de una «red de asociaciones culturales de carácter popular» a principios de siglo. Según este autor, que se basa en datos proporcionados por el Instituto de Reformas Sociales, en 1916 aparecen 335 sociedades obreras en España bajo el epígrafe de «sociedades instructivo-recreativas». Un buen número de ellas, constata Guereña, aparecen bajo la denominación de «ateneo», «centro instructivo» o "círculo instructivo», y es significativo que se utilice en mucha menor medida el término "casino»" ${ }^{1}$.

La mayoría de estas entidades tenían una impronta interclasista y se declaraban formalmente apolíticas, aunque en algunos casos esto último solía «contradecirse en la práctica por una perceptible influencia republicana o radical» ${ }^{18}$. Siguiendo la división perfilada por Pere Solà, muchas de ellas se caracterizaban por su funcionalidad social «integradora» («reformistas» o «neutras», utilizando la terminología de este autor). Otras consideraban su labor de difusión cultural como una importante arma de emancipación social, desde presupuestos ideológicos que abarcaban desde el republicanismo al obrerismo, que en sus distintas opciones (anarquistas, socialistas, etc.) van a ir identificándose cada vez más con esta cruzada por la educación popular.

Todos estos centros desarrollaban en efecto una fecunda y variada actividad cultural que podía incluir cursos formativos, conferencias, debates, veladas lite-

16 GuereÑA, Jean-Louis: «Una aproximación a la sociabilidad popular», op. cit., p. 211.

17 GuereñA, Jean-Louis: «Las Casas del Pueblo y la educación obrera a principios del siglo XX», Hispania, Madrid, LI/2, nº 178, 1991, pp. 662-665.

18 URÍA, Jorge: «La cultura popular en la Restauración. El declivé de un mundo tradicional y el desarrollo de una sociedad de masas», en SUÁREZ CoRTINA, Manuel (Ed.): La cultura española en la Restauración (I Encuentro de Historia de la Restauración), Santander, Sociedad Menéndez Pelayo, 1999, p. 125. También, de este mismo autor: Una bistoria social del ocio. Asturias, 1898-1914, Madrid, Publicaciones Unión-Centro de Estudios Históricos, 1996, pp. 254-255. 
rario-artísticas, creación de orquestas y grupos corales, puesta en marcha de bibliotecas "populares», etc. Y, si tal como señala Solà, «las alternativas culturales y educacionales, como las políticas y sociales, de la clase obrera, necesitaban, necesitan, un soporte institucional y asociativo» ${ }^{19}$, este soporte básico lo conformaban sin duda los numerosos casinos, ateneos y sociedades levantados durante las últimas décadas del siglo XIX y primeras del XX. Otra división de las entidades de culturización obrera utilizada por Solà haría referencia a aquéllas de carácter «autónomo» — conducidas por la misma clase trabajadora- y las de condición "heterónoma», dirigidas y promocionadas por elementos externos a ésta ${ }^{20}$.

Esta «red asociativa popular» actuaría como uno de los pilares fundamentales en el proceso de educación y formación de la clase obrera:

«[...] Des d'una concepció àmplia del fet cultural-educatiu, és evident que, a la fase prèvia a l'imperi dels mass media moderns i quan l'escolarització pública no havia assolit encara el nivell dels darrers quaranta anys, la difusió de la cultura o de la instrucció populars passava en bona mesura per l'oportunitat culturitzadora propiciada per la xarxa associativa» ${ }^{21}$.

No conviene olvidar, sin embargo, que el ateneo no era sino uno de los tipos organizativos claves dentro de la red de asociaciones populares «especializadas» en el ámbito de la cultura y el ocio. Las sociedades «instructivorecreativas» ocupaban un buen segmento del asociacionismo popular (otro sería, sin duda, el mutualismo y el cooperativismo), pero en buena parte de ellas no primaban las alternativas instructivas de uso del tiempo libre, sino el componente lúdico o recreativo: entidades deportivas o musicales, sociedades de baile o teatro, etc. Unas y otras coincidían, sin embargo, en su objetivo fundamental: la provisión de bienes y servicios de ocio a las clases populares, en un combate cada vez más enconado con las emergentes industrias relacionadas con el ocio (espectáculos teatrales y musicales, deportes, cine, etc.), como ha subrayado acertadamente Jorge Uría ${ }^{22}$.

Tal como señalábamos antes, muchos de los ateneos y centros culturales "populares» mencionados compartían desde fines del XIX (aunque no todos: conviene insistir en la necesidad de tener en cuenta la importancia clave de los ateneos

19 SolÀ, Pere: «Acerca del modelo asociativo de culturización popular de la Restauración», en GuereÑA, Jean-Louis y TIANA, Alejandro (eds.): Clases populares, Cultura, Educación. Siglos XIX y XX. Coloquio Hispano-Francés (Casa de Velázquez, Madrid, 15-17 junio de 1987), Madrid, Casa de Velázquez-U.N.E.D., 1989, p. 397 . Ver también, de este autor: Els ateneus obrers $i$ la cultura popular a Catalunya (1900-1939). L'Ateneu Enciclopèdic Popular, Barcelona, La Magrana, 1978, p. 46.

20 SOLÀ, Pere: Itineraris per la sociabilitat, op. cit., p. 255.

21 SOLÀ, Pere: Història de lassociacionisme català contemporani. Barcelona $i$ les comarques de la seva demarcació, 1874-1966, Barcelona, Generalitat de Catalunya, 1993, p. 16.

22 URÍA, Jorge: «La cultura popular en la Restauración», op. cit., pp. 125-126.

Hispania, LXIII/2, núm. 214 (2003) 467-484 
«neutros» o «reformistas» como modelo de culturización popular) una ideología progresista y se movían en unas coordenadas similares - «interclasistas, progresistas, republicanas, socialistas, laicistas, anticlericales»-, que eran en las que se desenvolvía, por otra parte, un "proceso de culturización obrera» no autónomo ${ }^{23}$. Y Pere Solà hace referencia en otro de sus trabajos a lo que denomina un «model d'influència creixent, el que hem denominat "paradigma associatiu republicà", caracteritzat per un projecte politico-cultural laic oposat al de l'associacionisme catòlic tradicional, i marcat també per la puixança de la sociabilitat obrera organitzada - mutualisme i cooperativisme-sindicalisme agrari-i per la florida d'un cada cop més vigorós associacionisme juvenil (esportiu i altre)» ${ }^{24}$.

El objetivo fundamental de estas entidades era también aunar el esparcimiento y la «diversión convivencial» con la cultura y la educación (es decir, trataban de compatibilizar «instrucción» y «recreo»). Por lo tanto, no abandonaban las actividades recreativas, pero éstas se veían limitadas en muchos casos al café y al juego (no de apuesta). El afán por la automejora social e individual a través de la educación legitimaba esta sociabilidad desde el punto de vista moral. Ello no quiere decir, como vemos, que desde este entramado asociativo popular u obrerista no se intentaran satisfacer también las necesidades de ocio de sus afiliados, a menudo en mucha mayor medida que la que pudiera deducirse de las formulaciones estatutarias o las declaraciones de intenciones de buena parte de estas agrupaciones.

Se consolida así un modelo asociativo, de gran éxito y prestigio entre los trabajadores españoles hasta la guerra civil: el ateneo «popular» u «obrero», centro de difusión cultural y de formación extraescolar y dinamizador de la educación popular. Si bien, como subraya Pere Solà, los ateneos «neutros» entran en crisis en las primeras décadas del siglo $\mathrm{XX}^{25}$, no ocurre lo mismo con toda una serie de entidades comprometidas en la promoción cultural de las clases populares (actuando muchas veces como centros de extensión universitaria y «universidades populares»), desde una perspectiva progresista y obrerista, pero al mismo tiempo apartidista y ecléctica, que continuarán desarrollando sus actividades hasta los años de la contienda. Un ejemplo emblemático de este tipo de asociaciones será el Ateneu Enciclopèdic Popular de Barcelona, que se convertirá casi en un modelo de funcionamiento con sus diversas secciones dedicadas a numerosas y diferentes actividades culturales y su apuesta decidida por la extensión educativa ${ }^{26}$.

23 SOLÀ, Pere: «Acerca del modelo asociativo», op. cit., p. 398

24 SOLÀ, Pere: Itineraris per la sociabilitat, op. cit., p. 470.

25 SOLÀ, Pere: Els ateneus obrers, op. cit., pp. 79-81.

26 Ibid., pp. 97-201. Además de este trabajo clásico de Solà, ha aparecido recientemente un estudio exhaustivo de la trayectoria y actividad de esta institución a lo largo de su historia: AISA, Ferran: Una bistòria de Barcelona. Ateneu Enciclopèdic Popular (1902-1999), Barcelona, Virus Editorial-Ateneu Enciclopèdic Popular, 2000.

Hispania, LXIII/2, núm. 214 (2003) 467-484 
Por otra parte, un claro ejemplo de la pervivencia del modelo ateneístico dentro de la militancia obrerista con una definición ideológica más precisa será la fundación por parte de anarquistas y anarcosindicalistas de toda una red de ateneos que recibieron en las primeras décadas del siglo XX diversas denominaciones: «libertarios», «sindicalistas», «racionalistas», y que tenían en la educación del individuo «consciente» su principal ámbito de actuación y razón de ser. Estos ateneos eran centros de difusión y adoctrinamiento ideológico, así como núcleos de formación del militante, pero también actuaban como entidades de divulgación cultural en un sentido general ${ }^{27}$.

La heterogeneidad de estas entidades era muy acusada, tanto en su orientación (dentro de las diversas tendencias dentro del movimiento libertario: «faístas», «sindicalistas», «individualistas», etc.) como en sus funciones, características, etc. Algunos ateneos podían actuar simplemente como la proyección de la acción de un grupo ácrata, "correas de transmisión» de la F.A.I. o de las Juventudes Libertarias, centros de propaganda, cobertura de las actividades revolucionarias en tiempos difíciles o como domicilio y lugar de reunión de núcleos de militantes y jóvenes libertarios. En otros casos, se hallaba más acentuada la tarea de difusión educativa antes mencionada, en forma de creación de bibliotecas o escuelas para trabajadores.

Pero en general, los ateneos puestos en marcha por los militantes anarquistas y anarcosindicalistas españoles en estos años solían responder a las dos funciones básicas ya citadas. Por un lado, funcionaban como canales «extrasindicales» donde se socializaba y formaba (convirtiéndose así en lugares de aprendizaje y «fraguas» de anarquistas) a la propia militancia mediante el despliegue de diversas prácticas sociales y culturales que cohesionaban a la «familia» ácrata. Esto incluía no sólo la transmisión de los postulados ideológicos del pensamiento anarquista o de las estrategias y consignas de la organización confederal y ácrata, sino que abarcaba también la difusión teórica y práctica de una serie de actitudes y valores que implicaban la reformulación en clave progresista y revolucionaria de determinados comportamientos sociales, conductas personales y patrones de convivencia en la vida diaria: sexualidad y relaciones de pareja, rol social de la mujer, salud e higiene, naturismo, acceso a la cultura y la ciencia, secularización de los hábitos y costumbres, etc.

Por otro lado, cabe mencionar su cometido como instrumentos de extensión cultural y de promoción educativa de las clases trabajadoras. En ellos se luchaba contra el analfabetismo, se organizaban actividades como cursos o conferencias, se creaban escuelas racionalistas, etc., aunque no era éste el único ámbito que pretendían actuar, ya que entre sus objetivos se encontraba el enraizarse plenamente en la vida cotidiana de las barriadas populares de las ciu-

27 Navarro Navarro, Francisco Javier: Ateneos y Grupos Ácratas. Vida y Actividad Cultural de las Asociaciones Anarquistas Valencianas durante la Segunda República y la Guerra Civil, Valencia, Generalitat Valenciana (Biblioteca Valenciana), 2002, 610 p.

Hispania, LXIII/2, núm. 214 (2003) 467-484 
dades donde surgían, ofreciendo a los trabajadores — siempre en función de sus posibilidades, casi siempre muy limitadas - una oferta social, cultural y de ocio de vocación emancipatoria.

Los ateneos anarquistas y anarcosindicalistas se inscribían así plenamente en una amplia tradición, tanto en las formas asociativas empleadas, como en el contenido de una "extensión cultural» (cursillos para adultos sobre las más variadas materias, escuelas, bibliotecas, etc.), que tiene como destinatarias a las clases populares. Los libertarios usarán precisamente el término «ateneo» para designar a sus centros culturales más emblemáticos y se insertarán así, como vimos, en un molde cultural ya existente (el del ateneo o centro de estudios "popular» y "obrero»), readaptándolo en función de sus propios intereses y necesidades (y de sus postulados ideológicos específicos), pero manifestando siempre, al mismo tiempo, su predilección por un prototipo de centro que colocaba en teoría la difusión cultural y las prácticas educacionales como su objetivo principal más allá de las «luchas partidistas».

En general, la trayectoria de estos ateneos (y la suerte de sus proyectos e iniciativas culturales) estuvo muy condicionada por su habitual precariedad, la escasez de medios económicos y humanos, la dependencia de la suerte de las organizaciones libertarias a las que estaban vinculadas y una inestabilidad casi permanente, muy condicionada por el contexto político y legal en que desarrollaban su labor, y en el que se alternaban - como sucedió durante la Segunda República- los períodos de represión gubernamental con los de relativa «normalidad» y relanzamiento de sus proyectos sociales y culturales.

\section{Centros obreros Y «CASAS del Pueblo»}

Todo el proceso analizado hasta aquí es paralelo a la tendencia progresiva entre las sociedades obreras a hacerse cargo de sus propias necesidades en materia de cultura y ocio, cada vez más visible a finales del siglo XIX y principios del XX. Al incremento cuantitativo de estas entidades experimentado en esa época, hay que añadir el interés creciente por parte de las organizaciones obreras de asumir por sí mismas las demandas de las clases populares, no sólo en la defensa del trabajo o el salario, sino en otros ámbitos básicos como la lucha por la mejora en las condiciones de vida, la vivienda, el ocio o la cultura.

De esta manera, van incorporando mutuas o cooperativas en sus entramados asociativos, pero también actividades relacionadas con la instrucción o el recreo «útil» y «consciente» de los trabajadores. Sociedades obreras y sindicatos (socialistas, anarquistas, republicanos, etc.) pasarán así a organizar en muchos casos conferencias, cursillos, veladas teatrales y musicales, lecturas comentadas, etc., y a fundar incluso bibliotecas y escuelas propias. La creciente inversión de esfuerzos y energías en este sentido venía abonada sin duda por una confianza cada vez mayor de las organizaciones políticas y sindicales del movimiento 
obrero en las posibilidades de la instrucción pública y la cultura, así como en la consideración de éstas como instrumentos auténticamente revolucionarios, expectativas que acabaron por otorgarles una importancia similar a la de otros aspectos de la lucha por la emancipación de los trabajadores ${ }^{28}$. No obstante, esta incorporación de actividades culturales a la vida societaria no se circunscribe en absoluto a las entidades obreras, sino que es un fenómeno común que va cobrando importancia en general en las estrategias y prácticas de las redes asociativas de diferentes organizaciones políticas desde finales del siglo XIX y principios del $\mathrm{XX}^{29}$.

Los locales de los centros obreros intentarán, por tanto, satisfacer en la medida de lo posible estas nuevas necesidades, convirtiéndose no sólo en lugares de «reuniones políticas o sindicales», sino también en espacios de «relación y de sociabilidad obrera en un sentido muy amplio» en los que también se desplegaban prácticas culturales. El objetivo último era, en buena medida, disponer de una trama asociativa que permitiera atender a reivindicaciones laborales y sociales generales y que sirviera asimismo como plataforma de difusión de los postulados ideológicos propios, a la vez que se satisfacían las demandas educativas y de ocio y se desarrollaba una sociabilidad específica que actuaba como factor de identidad y cohesión del grupo.

Resulta lógico, por tanto, que una de las aspiraciones presentes en el mundo obrero fuera crear centros polifuncionales que pudieran responder a todos estos requisitos. Y, tal como señala Pere Gabriel, el modelo «disponible» de centro obrero a principios del siglo XX no era en definitiva sino el del republicanismo popular decimonónico, similar a su vez al que ya había desplegado el ya mencionado asociacionismo abierto y multifuncional en décadas anteriores. En él se situaban, «alrededor, como siempre de un salón de actos (eje para la celebración de fiestas, mítines, conferencias, teatro), despachos para las secretarías de las sociedades obreras y para los servicios accesorios diversos, locales para la pequeña cooperativa y para el café» ${ }^{30}$. Si comparamos esta descripción con la de los centros federales de las décadas de los ochenta y noventa del siglo anterior (sala/café al pie de la calle con piezas anexas para aulas de enseñanza y piso superior o "planta noble» con sala de actos central, pequeños despachos para los comités y biblioteca), hallaremos la prueba de las continuidades comentadas ${ }^{31}$.

Dentro del ámbito de la izquierda, y vinculadas también a este asociacionismo obrero, comenzaron a desarrollarse a partir de la primera década del siglo XX tramas asociativas que reproducían a su vez ese prototipo de centro multifuncional y que servían además como espacios de desarrollo de una de-

\footnotetext{
28 Puede encontrarse un balance de la historiografía sobre esta cuestión en: TIANA FERrer, Alejandro: «Movimiento obrero y educación popular en la España contemporánea», Historia Social, Valencia, $n^{\circ} 27,1997$.

29 Ver URíA, Jorge: Una bistoria social del ocio, op. cit., p. 179.

30 GABRIEL, Pere: «Sociabilidad obrera y popular y vida política en Cataluña», op. cit., p. 154.

31 Ibid., p. 149.
} 
terminada cultura política. Entre ellas, podríamos mencionar, por ejemplo, los círculos y casinos levantados por el republicanismo lerrouxista o blasquista y las Casas del Pueblo (instituidas por republicanos y socialistas). Estos centros intentaban convertirse en los puntales de la institucionalización de una identidad popular y obrera. Como parte de este proceso, trataban de aunar el talante instructivo y formativo, que subrayaban una y otra vez - asignando un papel relevante a la culturización de las clases populares-, con la necesidad de satisfacer las demandas de sus militantes, afiliados y simpatizantes en materia de ocio y recreo, lo que les llevaba a desempeñar en muchos casos funciones propias del modelo del «casino».

Así ocurría, por ejemplo, en los círculos republicanos y (de manera menos evidente pero igualmente detectable) en las Casas del Pueblo socialistas. En definitiva, estos centros pretendían proporcionar «todos los medios - desde el bar a la escuela, pasando por el orfeón y el teatro- para una 'vida común mejorada y educadora' ${ }^{32}$. Esa lucha por la conquista del tiempo libre por parte de estos sectores no era ajena, como comentábamos, al desarrollo paralelo en las grandes urbes de centros de ocio cada vez más numerosos y diversificados (teatros, cafés cantantes, espectáculos de variedades, salas de cine, etc.).

Detengámonos ahora brevemente en un modelo de centro obrero con vocación centralizadora, totalizadora y multifuncional, que se consolidará en las primeras décadas del siglo y que se convertirá en un referente ineludible de la sociabilidad obrera militante: las Casas del Pueblo socialistas, centros que reunían sociedades de trabajadores (vinculadas o próximas a la U.G.T.), agrupaciones del P.S.O.E., cooperativas, mutualidades, etc. Asimismo, además de su componente sindical, político y asistencial, conviene subrayar la orientación cultural e instructiva de estas entidades, clara y evidente desde su origen. Tal como señala Jean-Louis Guereña, "núcleos de difusión cultural y formación militante, estos centros obreros concretan una nueva sociabilidad donde la educación, en sentido amplio, desempeña un papel central»33.

Ya a principios del siglo XX, algunas Casas del Pueblo habían constituido escuelas para niños y adultos, rondallas y orfeones, cuadros artísticos, grupos excursionistas, etc. Así, por ejemplo, la Casa del Pueblo de Madrid (inaugurada en 1908) integraba en su seno asociaciones culturales y educativas como la Asociación Artístico-Socialista, el Orfeón Socialista Madrileño, las Escuelas Laicas, la Escuela Nueva, etc. Círculos y agrupaciones socialistas y núcleos de juventudes complementaban esta trama asociativa. Las Casas del Pueblo contaban, en definitiva, con un dispositivo educativo (escuelas) y cultural (biblioteca, cuadro artístico, orfeón) propio y entre sus actividades figuraban veladas poéticas y teatrales, conferencias, clases, excursiones, etc.

32 MAURICE, Jacques: «Propuestas para una historia de la sociabilidad», op. cit., p. 142.

33 GuereñA, Jean-Louis: «Las Casas del Pueblo y la educación obrera», op. cit., p. 655. 
Una característica central de las Casas del Pueblo socialistas era su multifuncionalidad. Eran no sólo espacios de difusión cultural, sino también lugares de reunión y debate, así como "focos de formación y concienciación política» ${ }^{34}$. En ellas se proporcionaba además una serie de servicios a los afiliados: economatos y cooperativas de consumo, mutualidades y consultorios médicos, solidaridad económica, asesorías jurídicas, etc. Conviene subrayar que las Casas del Pueblo actuaban también como lugares de encuentro social y de esparcimiento «a modo de los cafés y casinos; como alternativa a la taberna proletaria tradicional o las nuevas formas de los cafés-cantantes y cabarets»35. Casi todos sus locales contaban con un espacio dedicado a café. Parece incluso que la venta y el consumo moderado de alcohol eran permitidos en estos centros; no ocurría así, sin embargo, en lo que se refiere a los juegos de azar.

Esta pluralidad de funciones convertía a las Casas del Pueblo en «el centro de una red o sistema de relaciones políticas, sindicales, económicas y culturales y de organismo o servicios, en una especie de microcosmos o ciudadela - La 'Nueva Jerusalén', 'islote de autonomía obrera'» ${ }^{36}$. Estos «templos» y «palacios» (espacios de los que se recoge de alguna manera la carga simbólica) obreros no constituían sólo, para el socialismo español, lugares destinados a las actividades comentadas, sino que ya su propia existencia y la imagen que proyectaban (la magnitud del edificio, su ubicación, su fachada, sus interiores) eran un emblema de prestigio, un signo de la potencia de la clase obrera y del movimiento socialista. Y, según Manuel Pérez Ledesma, las Casas del Pueblo pasaron a ser uno de los más importantes símbolos definidores de la identidad socialista:

«Se habían convertido en el lugar sagrado en el que la clase obrera, o mejor su fracción organizada bajo el liderazgo socialista, se constituía como tal, al tiempo que marcaba su alejamiento del resto de la sociedad» ${ }^{37}$.

Así pues, las Casas del Pueblo no eran solamente espacios asociativos que intentaran dar respuesta a una serie de necesidades que habían ido surgiendo entre la clase trabajadora y que abarcaban ámbitos tan básicos como la lucha por la mejora de las condiciones de trabajo y de vida, la solidaridad con los desempleados, la asistencia en caso de enfermedad o fallecimiento, la vivienda, etc. El combate para satisfacer estas demandas se había convertido en un esfuerzo básico del movimiento obrero, como ya mencionamos. Pero no era el único.

\footnotetext{
34 LUIS MARTín, Francisco de y ARIAS GonZÁleZ, Luis: Las Casas del Pueblo socialistas en España (1900-1936), Barcelona, Ariel, 1997, p. 53. Seguimos en estas líneas las reflexiones de estos autores en torno a la multifuncionalidad de las Casas del Pueblo (ver pp. 52-69).

35 lbid., p. 59.

36 Ibid., p. 67.

37 PÉreZ Ledesma, Manuel: «La cultura socialista en los años veinte», en GARCía Delgado, José Luis (Ed.): Los orígenes culturales de la II República. IX Coloquio de Historia Contemporánea de España dirigido por Manuel Tuñón de Lara, Madrid, Siglo XXI, 1993; p. 185.
}

Hispania, LXIII/2, núm. 214 (2003) 467-484 
Otro era, sin duda, la lucha por el cambio de hábitos sociales y la afirmación de nuevas prácticas de sociabilidad entre la clase obrera, que implicaran, por ejemplo, una manera más edificante de emplear el tiempo libre y una apuesta por la instrucción y la autoformación, ámbitos que también se intentaban cubrir desde estos espacios.

Asimismo, las Casas del Pueblo eran focos de difusión ideológica de los principios, valores y estrategias del socialismo entre los trabajadores. Todo ello formaba parte de un proyecto más amplio: la consolidación de una identidad socialista y de los vínculos de pertenencia al movimiento, reforzada mediante prácticas y rituales de concienciación y afirmación colectiva de la más diversa índole ${ }^{38}$, así como por la difusión de lo que se suponía un «estilo» de comportamiento y conducta socialista.

Aunque no es posible extraer conclusiones que se extiendan al conjunto de los movimientos anarquista y socialista respectivamente, resulta evidente por tanto que Ateneos libertarios y Casas del pueblo eran la expresión más clara de dos modelos diferentes de comportamiento asociativo por lo que se refiere al ámbito de la cultura y la formación de militantes y trabajadores en general. De entrada, una posible comparación entre ambos centros presenta algunos problemas, ya que las características y objetivos de unas y otras entidades distaban de ser similares. Francisco de Luis Martín y Luis Arias González intentan esbozar algunas de las semejanzas y diferencias entre estos centros y observan en ambos tipos de sociedades una preocupación común por «fundar escuelas, orfeones, coros, agrupaciones teatrales, grupos de lectura, bibliotecas, etc.», lo que convierte a estos dos modelos de centros en focos de difusión cultural y de prácticas educacionales alternativas en el mundo obrero. Estos historiadores consideran, sin embargo, que la no promoción ateneística de mutualidades y cooperativas y la ausencia del café en las agrupaciones libertarias constituyen diferencias fundamentales, a las que habría que añadir la insistencia anarquista en temas como «el esperantismo, el naturismo, el vegetarianismo, el nudismo, etc.»39.

La finalidad de los últimos era fundamentalmente formativa (lo cual no quiere decir que no desempeñaran otras funciones) y no presentaban el carácter centralizador y unificador que distinguía, como vimos, a las Casas del Pueblo (que eran a la vez sindicatos, agrupaciones políticas, centros de asistencia, etc.). Quizás resulte algo más operativa una comparación de conjunto entre el modelo asociacionista libertario y el del socialismo. El primero se perfila como paralelo al que nos proporcionan las Casas del Pueblo socialistas, por ejemplo, que tienden a unificar en sus locales todas las iniciativas y proyectos, incluidos los culturales.

Podríamos aducir diversas razones para explicar por qué el anarcosindicalismo no contó con centros similares. Sin duda, tendríamos que aludir a las

38 Luis Martín, Francisco de y Arias GonZÁlez, Luis: Las Casas del Pueblo socialistas, op. cit., pp. 71-72.

39 Ibid., p. 44.

Hispania, LXIII/2, núm. 214 (2003) 467-484 
dificultades materiales, la inestabilidad legal y política, la represión, etc. Pero también a diversas características ideológicas y organizativas propias del movimiento confederal y del asociacionismo libertario, que tuvieron asimismo su reflejo en la actividad cultural. Entre ellas, lo que podríamos calificar como «descentralización» o «policentrismo» asociativo. Centenares de sociedades obreras y sindicatos, grupos anarquistas, agrupaciones juveniles o ateneos, desarrollaron proyectos y actividades culturales propios, muchas veces de manera autónoma y aislada.

Otros elementos a tener en cuenta en este sentido fueron, sin duda, la importancia del grupo en la sociabilidad libertaria o la apuesta por una infraestructura de orientación específicamente cultural y formativa, como es el caso de los ateneos. Esto no equivale a decir que en el mundo libertario no se experimentara - al igual que en resto del movimiento obrero organizado- la necesidad de poseer esos centros propios amplios y multifuncionales, reproducidos también por el anarcosindicalismo cuando las circunstancias así se lo permitieron. La trashumancia y la movilidad obligada en muchos casos, la falta de un domicilio fijo y la precariedad de los locales propios, provocaban que ésta fuera, en realidad, una aspiración largamente sentida. Asimismo, durante los años de la guerra civil, asistimos a una clara tendencia hacia la centralización en el tejido asociativo libertario, proceso impulsado sin duda por el contexto bélico y los condicionantes impuestos por la evolución política y social en la retaguardia republicana, y que se vivió con no pocas tensiones y dificultades en las filas ácratas.

No obstante, a la altura de la década de los años treinta, y con el horizonte final de la guerra civil (que marcará con su desenlace un lógico punto de ruptura en estos comportamientos asociativos), la nota dominante en el asociacionismo popular y obrero - y en concreto en aquél más o menos relacionado con la cultura y el ocio - era la diversidad formal, así como la continuidad de una serie de tradiciones en este ámbito. En primer lugar, seguían disfrutando de buena salud los modelos clásicos del asociacionismo popular abierto y multifuncional ya mencionados, renovados ahora, eso sí, con nuevas formas que iban difundiendo la modernización de los comportamientos sociales y culturales y la consolidación y extensión de una cultura plenamente urbana durante el período de entreguerras (asociacionismo deportivo, excursionismo, etc.) ${ }^{40}$.

En relación con lo expuesto hasta aquí, cabe subrayar también que el modelo del «ateneo» gozaba todavía de un considerable prestigio y vigencia en los medios obreros, como se demostrará a partir de 1931, con especial arraigo en aquellas zonas donde este prototipo asociativo tenía una amplia tradición, como es el caso del área mediterránea. La característica central del entramado ateneístico siguió siendo su heterogeneidad. Continuaron funcionando ateneos «populares» y «obreros» de carácter más o menos ecléctico, muchos ellos here-

40 GABRIEL, Pere: «Sociabilitat de les classes treballadores», op. cit., pp. 106-107. 
deros del heterogéneo mundo del republicanismo federal y el librepensamiento, a la vez que desde instancias más «militantes» y "partidistas» se siguió recurriendo a este prototipo asociativo. Pere Gabriel señala en este sentido:

«Significativament, però, el gran model cobejat també per la militància obrera era el del centre fonamentalment cultural, obert a la vida més quotidiana i popular de les famílies obreres [...]. Cal situar en aquest punt els múltiples i sovint precaris intents d'ateneus llibertaris o entitats d'activitat cultural socialista o comunista de finals del vint i els anys trenta» ${ }^{41}$.

Un ejemplo de ello fue el resurgimiento de la red de ateneos libertarios en estos años. Otro fue la creación de ateneos obreristas, de impronta socialista, comunista, sindicalista, etc. A menudo, estas entidades no dependían directamente de las redes de los grandes partidos de izquierda o sindicatos y se convirtieron en abanderados de una cultura política obrera amplia en el nuevo contexto de la década de 1930, como ocurrió con los ateneos «aliancistas» impulsados por los sindicalistas treintistas o los militantes poumistas en zonas como Cataluña o el País Valenciano en este período.

${ }_{41}$ Ibid., p. 112. 